\title{
Musicotherapy: Is rhythm able to inhibit inhibitors?
}

\section{Diego Liberati* \\ Research Director National Research Council of Italy, Italy}

Parkinsonians and Aphasics get often able to move and talk, respectively, with music. Looking at that is fascinating: it looks like if the breath of the Spirit would suddenly have given life to an almost inanimate creature! How it works? It is not completely clear, but, objectively, it seems to work. It looks like as if a motor / phasic pattern is not destroyed, just permanently inhibited, and music is in turn able to inhibit the inhibitor: the Parkinsonian dances, the Aphasic sings. Then, the dancer comes to walk, the singer to talk. This is suggestive about the possibility that dance or running - anyway continuous rhythmic movement - is the ground of our movement: brain evolved to move, in order to escape predators, catch preys and mate, and running, dancing, walking at a given pace is more stable than just standing, like for a bicycle, both having just two "points" of touching the ground, instead of the three needed to stay still passively. Starting or stopping walking is more demanding - in term of control - than just keeping doing? A train of evoked potential, accorded to the natural frequency of the processing neural network - around $10 \mathrm{~Hz}$ for occipital visual cortex for instance - is less demanding than single stimuli, each one eliciting the $10 \mathrm{~Hz}$ frequency - peaking about 100 milliseconds after the stimulus at $\mathrm{P} 100$ then immediately decaying.

This even suggests that our first natural communication language would have been singing, like birds, then superposing words, finally became able to flu alone: probably music and rhythm restore such a phylogenetic path inhibiting the inhibition to sing or dance provoked either by the sudden stroke in Aphasics or by the chronic degeneration in Pakinsonians. Rhythm is in fact a kind of breath, and relaxed relaxing breath is rhythmic, entraining the parasympathetic high frequency in the heart rate variability spectrum as opposed to the sympathetic low frequency witnessing stress. Thus, musicotherapy may also be view, at least in part, as a kind of emotionally dear vagal stimulation, not so far from the traditional vagal stimulation sometimes used in pharmacy-resistant epilepsy: apparently, 3 very different pathologies, probably related by a different - but commonly grounded - problem of rhythm: electrically, epilepsy cortically appear in EEG just as a diffused hyper-sincronisation of the brain around $3 \mathrm{~Hz}$ triggered by the focus. Vagal stimulation in this view is a kind of defibrillator, as music could be for the inherited inhibition to move or talk. In Talmud, one of the worst consequences of evil would be music deprivation: "if we will have been bad, God will deprivate us of music": harmony will be lost, as we metaphorically say even in modern language. On the contrary, enthusiasm, also coming from musicotherapy in groups of both patients and therapists, and even just spectators, ethnologically is literally to breath in god - En Thous i Asthm - at His rhythm! A Community - a group in therapy - often gets better results than a single patient: would it be wise to even mix speaking Parkinsonians and not leg-plegic Aphasics? If really the problem is the same of rhythms, maybe the latter could drive Parkinsonians to dance, while the former could drive Afasic to talk, vicariating each other the main impairment through the respective residual ability, emotionally sustaining each other on the ground of the common - though different - disease.
Copyright: (C)2017 Liberati D. This is an open-access article distributed under the terms of the Creative Commons Attribution License, which permits unrestricted use, distribution, and reproduction in any medium, provided the original author and source are credited.
Correspondence to: Diego Ettore Liberati, $\mathrm{PhD}$, Research Director National Research Council of Italy, Italy, E-mail: diego.liberati@polimi.it

Received: October 26, 2017; Accepted: November 13, 2017; Published: November 17, 2017 